\title{
Direitos humanos e saúde: 70 anos após a Declaração Universal dos Direitos Humanos
}

\author{
Human rights and health: seventy years after the Universal Declaration of \\ Human Rights
}

\section{Derechos humanos y salud: setenta años después de la Declaración Universal de los Derechos Humanos}

\author{
Maria Helena Barros de Oliveira ${ }^{1, a}$ \\ mhelenbarros@globo.com | https://orcid.org/0000-0002-1078-4502 \\ Marcos Besserman Vianna ${ }^{1, b}$ \\ mbessa@ensp.fiocruz.br | https://orcid.org/0000-0001-9411-2086 \\ Nair Teles ${ }^{1, c}$ \\ ntelesuem@gmail.com | https://orcid.org/0000-0003-0481-504X \\ Felipe Rangel de Souza Machado ${ }^{1, d}$ \\ felipemachado@fiocruz.br | https://orcid.org/0000-0002-5028-8888 \\ Aldo Pacheco Ferreira ${ }^{1,}$ \\ aldopachecoferreira@gmail.com | http://orcid.org/0000-0002-7122-5042 \\ Fernando Salgueiro Passos Telles ${ }^{1, f}$ \\ fernando.telles@ensp.fiocruz.br | https://orcid.org/o000-0001-7943-8969 \\ Lucia Regina Florentino Souto ${ }^{1, g}$ \\ luciafsouto@yahoo.com.br | https://orcid.org/0000-0003-2270-8424
}

\footnotetext{
${ }^{1}$ Fundação Oswaldo Cruz, Escola Nacional de Saúde Pública Sérgio Arouca, Departamento de Direitos Humanos e Saúde. Rio de Janeiro, RJ, Brasil.

a Doutorado em Ciência pela Fundação Oswaldo Cruz.

${ }^{\text {b }}$ Doutorado em História das Ciências e das Técnicas e Epistemologia pela Universidade Federal do Rio de Janeiro.

${ }^{c}$ Doutorado em Sociologia pela Universidade Victor Segalin.

${ }^{d}$ Doutorado em Saúde Coletiva pela Universidade do Estado do Rio de Janeiro.

e Doutorado em Engenharia Biomédica pela Universidade Federal do Rio de Janeiro.

f Doutorado em Filosofia pela Universidade Federal do Rio de Janeiro.

${ }^{g}$ Doutorado em Ciência pela Fundação Oswaldo Cruz.
}

\section{Resumo}

A presente nota apresenta a discussão sobre a Declaração Universal dos Direitos Humanos desde sua assinatura em 1948, questionando a sua efetividade na luta por direitos e reconhecendo suas falhas ao que se refere a igualdade entre os sujeitos. Dessa forma ressalta os apagamentos que se escondem por trás de uma dita "universalidade" e reivindica a necessidade do debate, primeiramente, por dignidade - conceito que se torna inseparável do que se entende de fato por Direitos.

Palavras-chave: Direitos humanos; Dignidade; Justiça; Universalidade; Violências. 


\begin{abstract}
This note shows the discussion on the Universal Declaration of Human Rights since its adoption in 1948, questioning its effectiveness in the struggle for rights and acknowledging its failures on the equality between the individuals. In this way, the deletions hidden behind a so-called "universality" are highlighted, claiming first, the need of debating for dignity - a concept that becomes inseparable from what is in fact understood by Rights.
\end{abstract}

Keywords: Human rights; Dignity; Justice; Universality; Violence.

\title{
Resumen
}

La presente nota presenta la discusión sobre la Declaración Universal de los Derechos Humanos desde que fue adoptada en 1948, cuestionando su efectividad en la lucha por derechos y reconociendo sus fallas cuando refiriéndose a la igualdad entre los sujetos. De esa forma, se resalta la supresión que se esconde por detrás de una dicha "universalidad" y reivindica la necesidad del debate, primeramente, por dignidad concepto que se torna inseparable de lo que se entiende de of ahecho por Derechos.

Palabras clave: Derechos humanos; Dignidad; Justicia; Universalidad; Violencias.

Contribuição dos autores: Os autores são responsáveis por todo o texto.

Fontes de financiamento: Não houve.

Considerações éticas: Não há.

Agradecimentos/Contribuições adicionais: Não há.

Histórico do artigo: Submetido: 05.dez.2018 | Aceito: 06.dez.2018 | Publicado: 21.dez.2018.

Apresentação anterior: Não houve.

Licença CC BY-NC atribuição não comercial. Com essa licença é permitido acessar, baixar (download), copiar, imprimir, compartilhar, reutilizar e distribuir os artigos, desde que para uso não comercial e com a citação da fonte, conferindo os devidos créditos de autoria e menção à Reciis. Nesses casos, nenhuma permissão é necessária por parte dos autores ou dos editores.

Na busca da superação do caos que a humanidade atravessou com a Segunda Grande Guerra Mundial inscreve-se um novo caminho com a pactuação lançada pela Organização das Nações Unidas (ONU), no dia 10 de dezembro de 1948: a Declaração Universal dos Direitos Humanos.

Neste ano de 2018, comemoram-se 70 anos dessa Declaração em todo o mundo. A luta universal de diferentes países fez com que os direitos humanos se tornassem praticamente uma linguagem hegemônica da defesa intransigente da dignidade da pessoa humana. Entretanto, esse discurso é contraposto por uma cruel realidade, a da não efetivação dos direitos humanos ${ }^{1}$. Ao longo dos anos eles continuam sendo alvo de ataques de diversos matizes desde o seu início no século XVIII. Lynn Hunt² desenvolveu um importante trabalho mostrando o surgimento e a afirmação dos direitos humanos no mundo ocidental, mas apontando também que a reação ao seu desenvolvimento sempre foi vigorosa.

Nesse sentido, é fundamental reafirmarmos a importância da reflexão sobre justiça e dignidade humana. A afirmação de que "todos são iguais perante a lei", esconde o fato de que "os homens, de fato, não nascem livres nem iguais"3, mas apenas no contexto democrático algumas dessas diferenças podem ser minimizadas. Este foi, 
inclusive, o espírito da sociedade brasileira na luta contra a ditadura, o que permitiu inscrever, 40 anos depois, na Constituição de 1988, o artigo $6^{\circ}$ (definindo direitos sociais) que espelha e amplia o escopo dos direitos humanos presentes na Declaração de 1948. Apenas no contexto democrático a sociedade pode expressar seus anseios por direitos básicos das pessoas. Tal expressão é regida por uma significação de justiça que não deve traduzir ou representar os desejos, as preferências, a defesa de uma perspectiva, de algo, de alguém, de um grupo, mas deve ser construída por indivíduos autônomos e atribuída a si próprios e aos demais. E por entender que a existência humana é portadora de um valor intrínseco, que ela é um fim em si mesmo, o respeito pela humanidade acopla-se à percepção de justiça, e, por conseguinte, a dignidade humana a ela é incorporada, trazendo consigo o matiz de universalidade.

No caso dos direitos humanos, as noções de justiça e de dignidade humana são traduzidas por um conjunto de declarações, proclamações, cartas, de valor intrínseco. Elas constituem afirmações éticas diante da importância de certas liberdades, direitos e deveres, socialmente ratificados. E esse conjunto serve de referencial para legislações nacionais, para justificar e basear condutas, sanções, ações no âmbito internacional, mas não só, ele serve também para guiar e nortear condutas, escolhas, percepções de mundo. De uma forma geral, relacionam-se os diversos campos que compõem a vida cotidiana aos respectivos direitos inalienáveis do ser humano a serem observados.

A dignidade humana é, pois, inseparável do que se entende por justiça e direitos humanos e ela um dos poucos valores de concordância universal. É um princípio não questionável no plano político e legal, e independentemente das diferenças socioculturais há uma compreensão generalizada da inviolabilidade das pessoas. Justiça e dignidade humana compõem o núcleo central dos direitos humanos, pois aí subjaz uma certa ideia de humanidade. Assim, tanto o governo quanto as relações sociais devem se pautar de acordo com o respeito a particularidades e necessidades diversas.

No entanto, como afirma Bobbio 3 , "o problema fundamental em relação aos direitos do homem, hoje, não é tanto o de justificá-los, mas de protegê-los. Trata-se de um problema não filosófico, mas político”. A transposição do nível teórico para o prático encontra barreiras dos mais diversos tipos, uma delas, talvez a principal, é a necessidade de criação de empatia entre os seres humanos. Esta foi uma característica central para o surgimento da ideia de direitos humanos destacados por Lynn Hunt ${ }^{2}$. Ela mostra como, em determinado momento no século XVIII, as pessoas passaram a reconhecer o outro como semelhante a si. A repercussão disso foi tal que a partir daí até a tortura foi condenada nos procedimentos judiciais.

A despeito da hegemonia dos direitos humanos nos últimos 70 anos, Santos ${ }^{1}$ afirma que "a grande maioria da população mundial não é sujeito de direitos humanos. É objeto de discursos de direitos humanos". Neste sentido, na luta que deve ser travada contra a violação dos direitos humanos, em um primeiro momento, cabe enfrentar todas as formas de violências com as quais, hoje, ainda convivemos na sociedade. Facilmente, é possível perceber as várias formas de violências e agressões que se apresentam ferindo diretamente a dignidade do ser humano. Uma das manifestações dessas violências é, por exemplo, o sistema prisional com a superlotação que implica total desrespeito a direitos básicos, com especial destaque para as mulheres que não são respeitadas em seu momento mais especial - o do surgimento da vida -, e na maioria das vezes chegam a viver o momento do parto algemadas.

Cabe ressaltar também as violências contidas no mundo do trabalho, que resultam em acidentes de trabalho, doenças profissionais e do trabalho, além de assédios sexuais e morais, revelando desrespeito à dignidade das trabalhadoras e trabalhadores de forma extremamente desumana.

A negação de dignidade e autonomia, incluindo o tratamento forçado ou a sua institucionalização e a desconsideração da capacidade individual de tomar decisões, correspondem a uma atenção inadequada à saúde pública que, associada aos altos níveis de violência, pobreza e exclusão social contribuem para resultados nefastos sobre a saúde mental e física dos indivíduos. 
As violações aos direitos humanos criam um cenário de risco para pessoas com deficiências, populações indígenas, profissionais do sexo, pessoas que usam drogas, crianças e adolescentes, transgêneros e outros tantos discriminados, seja por gênero, sexualidade, raça/etnia ou opção religiosa.

Nesse contexto, compreender a saúde como um direito humano exige que os Estados garantam cuidados de saúde de qualidade, adequados, aceitáveis e acessíveis. E também que promovam ações para interferir nos determinantes subjacentes da saúde, tais como garantia de água potável, saneamento, informação e educação, segurança alimentar, habitação e igualdade de gênero.

O direito à saúde deve ser considerado sem discriminação em razão de raça, idade, etnia ou qualquer outra condição. A não discriminação e a busca da equidade exigem medidas para corrigir e adequar práticas ou políticas de cunho discriminatório.

Aliás, o filósofo Italiano Giogio Agambem ${ }^{4}$ tem chamado a atenção para a institucionalização cada vez mais forte da ideia de homo sacer: sujeitos matáveis cujas mortes não impõem penalidades nem culpa. Homo sacer é a materialização da política de segurança pública que pode levar a práticas de exceção permanente contra a população pobre. "Hoje a tortura é obrigação moral e obedece a uma razão instrumental"5. O autor salienta ainda o fato de que, por razões de Estado, hoje se impõe a tortura (e matar) como justificativa para salvar vidas. Nessa inversão de valores, "qualquer pessoa que combata a tortura é má, não presta serviço à humanidade"5. Nesta lógica, a moral não se volta mais para a defesa da vida (como pressupõe a própria Declaração dos Direitos Humanos), mas para o combate daqueles que ameaçam as vidas daqueles que têm valor. O valor da vida, portanto, não seria mais algo imaterial, autoevidente, para utilizar a expressão de abertura do livro de Lynn Hunt ${ }^{2}$, mas, ao contrário seria medido materialmente. Neste contexto, a ideia de dignidade humana perde sentido.

Ao compreendermos a saúde como um direito humano, exigimos que os Estados garantam acesso a cuidados de qualidade e também que promovam ações para interferir nos seus determinantes sociais. "Torna-se imperiosa a necessidade de colocar a dignidade das pessoas no centro da nova agenda de desenvolvimento sustentável. Essa abordagem é fundamental quando se consideram emergências de saúde pública como as epidemias, as violações maciças dos direitos sexuais e reprodutivos, as altas taxas de violência sexual, a falta de acesso ao aborto seguro, o sistema massivo do encarceramento, o modelo de guerra às drogas, racista e esteriotipado, entre tantas outras violações” .

O setor saúde é tão fundamental que o próprio ordenamento jurídico brasileiro reconhece que "os níveis de saúde expressam a organização social e econômica do País". O direito à saúde faz parte de um conjunto de direitos humanos acordados internacionalmente, e isso significa que alçar o direito ao mais alto padrão atingível de saúde (como prevê a Organização Mundial da Saúde) é fundamental e depende da realização de outros direitos humanos: os de alimentação suficiente e adequada, de moradia, de trabalho, de educação, enfim, de todos os direitos sociais previstos no artigo $6^{\circ}$ da Constituição Federal de 1988.

Violações aos direitos humanos podem ter graves consequências para a saúde. Por isso, a Emenda Constitucional $n^{0} 95$ fragiliza a observância dos direitos humanos, pois impede que o Estado realize as promessas de garantia da vida digna e de diminuição das desigualdades sociais. No contexto de envelhecimento da população brasileira, o limite dos gastos com saúde implicará a morte de parte significativa da população, relegando a garantia da vida, presente na Declaração a uma promessa inalcançável. Neste contexto, caberá ao mercado vender as ações de saúde àqueles que podem pagar por elas. Quem é capaz de pagar pela própria integralidade da saúde?

Bobbio argumentou que "os direitos do homem, por mais fundamentais que sejam, são direitos históricos, ou seja, nascidos em certas circunstâncias, caracterizadas por lutas em defesa de novas liberdades contra velhos poderes, e nascidos de modo gradual, não todos de uma vez e nem de uma vez por todas"3. Para o autor, o desenvolvimento da sociedade certamente gerará novas demandas por direitos e novas percepções sobre os direitos humanos, como "o direito de viver num ambiente não poluído"3, ou os "direitos da natureza". 
A primeira menção global à proteção ao meio ambiente ocorreu, em 1966, no Pacto Internacional de Direitos Econômicos, Sociais e Culturais, no qual o direito à saúde aparece ao lado do direito a ter um nível de vida adequado. $\mathrm{E}$ isto significa que o direito a uma vida digna corresponde a um meio ambiente equilibrado. Desde então, os direitos humanos e meio ambiente passaram a fazer parte das prioridades do Direito Internacional. A declaração de Estocolmo de 1972 fortalece essa compreensão ao afirmar que “o homem tem o direito fundamental à liberdade, à igualdade e a adequadas condições de vida num meio ambiente cuja qualidade permita uma vida de dignidade e bem-estar e tem a solene responsabilidade de proteger e melhorar o meio ambiente para a presente e as futuras gerações"9.

O desenvolvimento que procura satisfazer as necessidades da geração atual sem comprometer a capacidade das gerações futuras de satisfazerem as suas próprias necessidades significa possibilitar que as pessoas, agora e no futuro, atinjam um nível satisfatório de desenvolvimento social e econômico e de realização humana e cultural, fazendo, ao mesmo tempo, um uso razoável dos recursos da terra e preservando as espécies e os habitats naturais.

Santos denomina como "versão neoliberal dos Direitos Humanos"8 a posição que os fragmenta e busca retirar sua materialidade a partir da diminuição das políticas sociais. O autor ressalta que "ao longo dos anos, foi conquistando aceitação a ideia da indivisibilidade dos Direitos Humanos e, portanto, a ideia de que só o reconhecimento dos diferentes tipos de Direitos Humanos garante o respeito de qualquer um deles individualmente"8.

Só se avança na garantia de direitos exigindo-se mais, e essa exigência pela garantia de velhos e novos direitos tornou-se no Brasil uma atividade extremamente delicada. A ampliação da cena política e a aparição de novos ativistas fez Marielle Franco uma de suas vítimas. O contexto que se apresenta hoje no Brasil é extremamente hostil à defesa dos direitos humanos, talvez por isso mesmo a história nos tenha colocado a tarefa de lutar pela defesada democracia, pela materialidade dos direitos sociais e, especialmente, da saúde pública como um direito humano universal e igualitário.

\section{Referências}

1. Santos BS. Se Deus fosse um ativista dos direitos humanos. São Paulo: Cortez; 2013.

2. Hunt L. A invenção dos direitos humanos: uma história. São Paulo: Companhia das Letras; 2009.

3. Bobbio N. A era dos direitos. São Paulo: Civilização Brasileira; 1992.

4. Agamben G. Homo Sacer: o poder soberano e a vida nua I. Belo Horizonte: UFMG; 2004.

5. Hinkelammert F. Mercado versus direitos humanos. São Paulo: Paulus; 2014.

6. Oliveira MHB, Erthal RMC, Vianna MB, Matta JLJ, Vasconcellos LCF, Bonfatti RJ, organizadores. Direitos humanos e saúde: construindo caminhos, viabilizando rumos. Rio de Janeiro: Cebes, 2017. Introdução, direitos humanos e saúde: construindo caminhos, viabilizando rumos; p. 21-32.

7. Presidência da República (BR). Lei No 8.080, de 19 de setembro de 1990. Dispõe sobre as condições para a promoção, proteção e recuperação da saúde, a organização e o funcionamento dos serviços correspondentes e dá outras providências. DOFC. set. 1990; 18055. Disponível em: https://www. planalto.gov.br/ccivil 03/LEIS/L8080.htm

8. Santos BS, Chaui M. Direitos humanos, democracia e desenvolvimento. São Paulo: Cortez; 2013.

9. Conferência das Nações Unidas sobre o meio ambiente humano. Declaração de Estocolmo sobre o ambiente humano. 1972. Disponível em: http://www.direitoshumanos.usp.br/index.php/Meio-Ambiente/ declaracao-de-estocolmo-sobre-o-ambiente-humano.html 